\title{
CAFFEINE AND HUMAN CEREBRAL BLOOD FLOW: A POSITRON EMISSION TOMOGRAPHY STUDY
}

Oliver G. Cameron, M.D., Ph.D., Jack G. Model1, M.D., M. Hariharan, Ph.D Department of Psychiatry, University of Michigan Medical Center

(Received in final form July 24, 1990)

\section{Summary}

Positron emission tomography (PET) was used to quantify the effect of caffeine on whole brain and regional cerebral blood flow (CBF) in humans. A mean dose of $250 \mathrm{mg}$ of caffeine produced approximately a $30 \%$ decrease in whole brain CBF; regional differences in caffeine effect were not observed. Pre-caffeine CBF strongly influenced the magnitude of the caffeine-induced decrease. Caffeine decreased $\mathrm{p}_{2} \mathrm{CO}_{2}$ and increased systolic blood pressure significantly; the change in $\mathrm{p}_{\mathrm{a}} \mathrm{CO}_{2}$ did not account for the change in CBF. Smaller increases in diastolic blood pressure, heart rate, plasma epinephrine and norepinephrine, and subjectively reported anxiety were also observed.

Caffeine is a widely-consumed methylxanthine stimulant (1); average daily intake in the USA is $200-300 \mathrm{mg} /$ day (2). It is completely absorbed after oral adninistration and has a plasma half-life of 3-10 hours (3). Physiologically, caffeine decreases cerebral blood flow (CBF) (4-6), raises plasma epinephrine levels $(7,8)$, and functions as an antagonist at the adenosine receptor (9-12). Caffeine attenuates anoxia-induced (13) and hypercapnia-induced (14) increases in $\mathrm{CBF}$, but does not influence the autoregulatory effects on CBF which occur in response to hypotension (15).

Caffeine might also interact with the benzodiazepine macromolecular receptor complex through its adenosinergic effect (16). Caffeine can produce anxietylike symptoms $(17,18)$, especially in people with panic disorder $(19-21)$. It is controversial whether anxiety produces specific changes in CBF; some studies have reported effects $(22-25)$, but another has not (26).

The present study involved quantification and anatomical localization of the effects of epidemiologically relevant doses of caffeine on CBF by positron emission tomography (PET). Based on the observations that caffeine can be anxiogenic and that anxiety might affect CBF, we also intended to test the hypothesis that patients with panic disorder might have a different magnitude or anatomical pattern of CBF response to caffeine than normal subjects. However, because the effect of caffeine on CBF was so robust and

[Send reprint requests to: 01iver G. Cameron, M.D., Ph.D., Department of Psychiatry, University of Michigan Medical Center, Riverview Building, 900 Wa11 Street, Ann Arbor, Michigan 48109-0722.] 
the difference between patients and normal subjects was so small, we emphasize the results of intravenously administered caffeine on CBF as the sample of eight subjects rather than four patients and four normal controls; differences between patients and normal subjects are reported where they were observed. Because results with intravenous caffeine might not be comparable to the same dose given orally, two additional normal subjects received oral caffeine.

\section{Methods}

Eight subjects (two females and two males with panic disorder and four male normal subjects, mean age $=26.3$ years) received intravenous caffeine; two additional normal subjects (both male and both 24 years old) received oral caffeine. All 10 subjects reported average coffee intake (the major source of caffeine in most diets) of two or fewer cups per day, and all subjects were instructed to refrain from coffee consumption for 12 hours before the study. All were medically healthy and medication-free. The study was approved by the University of Michigan Medical Center Institutional Review Board for Use of Human Subjects in Research; all subjects gave written informed consent.

Each of the eight subjects who received intravenous caffeine (caffeine alkaloid in solution as caffeine sodium benzoate: Pasadena Research Laboratories, Inc., Pasadena, CA 91107) received the following four scans in one experimental session of 3-4 hours duration: (a) baseline, (b) after a saline placebo infusion, and (c \& d) 15 and 45 minutes after intravenous caffeine administration. Because patients with panic disorder might vary in their individual tolerances for the anxiogenic effects of caffeine, each patient was tested on a day prior to the PET study for ability to lie quietly after intravenous caffeine administration at graded, ascending doses; final tolerated doses for the four patients ranged from $120-350 \mathrm{mg}$, with a mean of $250 \mathrm{mg}$. Doses were $250 \mathrm{mg}$ each for the four normal subjects.

Subjects remained supine throughout the study; during the scans eyes were closed and room noise was minimized. During each scan arterial blood was sampled two minutes after injection of positron-labelled water $\left([150]-H_{2} 0\right)$ for blood gases, and plasma epinephrine, norepinephrine, and caffeine concentrations. Blood pressure, heart rate, and ratings of subjective anxiety from zero ("none") to 100 ("most ever") were determined at the end of each scan. Plasma caffeine was measured with HPLC; epinephrine and norepinephrine were measured by HPLC with electrochemical detection. Correction for changes in $\mathrm{p}_{\mathrm{a}} \mathrm{CO}_{2}$ was made using the following equation (26): $\mathrm{CBF}$ corrected to $\mathrm{p}_{\mathrm{a}} \mathrm{CO}_{2}$ of 40 torr $=\mathrm{CBF}$ observed $+1.8 \times\left(40-\mathrm{p}_{\mathrm{a}} \mathrm{CO}_{2}\right)$.

The last two normal subjects were scanned after receiving $250 \mathrm{mg}$ of orally administered caffeine. All of the same dependent variables were determined except catecholamines. Scans performed were: (a) baseline, and (b-d) at 15, 45, and 75 minutes after caffeine administration; no placebo scan was performed. For al1 10 subjects, there was a 14-minute minimum between all scans.

Scans were performed on a TCC PC-4600 tomograph with FWHM resolutions of approximately $10 \mathrm{~mm}$ axial and $11 \mathrm{~mm}$ in-plane. Data acquisition was continuous from 40 seconds to 6 minutes after infusion of $30 \mathrm{mCi}$ of $[150]-\mathrm{H}_{2} \mathrm{O}$. CBF and partition coefficients were estimated with a weighted integral technique involving a single-compartment blood flow model and use of radial artery blood to estimate the radioactivity input function to brain. Three rows 
of detectors plus two cross-slices produced five transverse scan slices from approximately 2.5 to $6.9 \mathrm{~cm}$ above the cantho-meatal line.

Regions of interest (ROIs) included whole brain (total area for all five slices), cerebral cortex (average flow in area of $25 \mathrm{~mm}$-deep computergenerated cortical peel for all five slices) and 12 ROIs which were localized with an anatomic atlas (27) and scaled to the dimensions of the PET images; these ROIs were right and left frontal Iobes, temporal lobes, occipital lobes, caudate nuclei, thalamus, and cerebeller hemispheres. Division of the computer-generated ROIs of the cerebral cortex into four quadrants permitted right/left and anterior/posterior comparisons.

PET image data were analyzed with and without correction for $\mathrm{p}_{2} \mathrm{CO}_{2}$, and with and without normalization to whole brain CBF. Because normalization did not affect results, only non-normalized data are reported. Statistical analyses were performed with between-within repeated-measures analyses of variance (ANOVAs--patients versus normals across four scan times), paired and unpaired t-tests, Pearson product-moment correlations, and simple linear regression. Significance levels are defined as $p \leq 0.05$ for two-tailed tests; trends are defined as $0.05<p<0.10$. Percentages of variance. accounted for by the significant F-ratios in the ANOVAs were estimated as eta 2 .

\section{Results}

In response to intravenously administered caffeine, whole brain CBF showed decreases of $31 \%$ at both 15 and 45 minutes after infusion without $\mathrm{PaCO}_{2}$ correction (repeated-measures $\mathrm{F}=18.1$, df $=3,18, \mathrm{p}<0.0001$; $\mathrm{eta}^{2}=$ 0.75 ) (Table 1), and $24 \%$ and $27 \%$, respectively, with correction (repeatedmeasures $F=11.6, d f=3,18, p<0.0003$; eta $\left.{ }^{2}=0.66\right)$. The pre-treatment mean whole-brain CBF level was $46.6 \mathrm{ml} / \mathrm{min} / 100 \mathrm{gm}$ of tissue. Based on $\mathrm{P}_{\mathrm{aCO}}$-corrected data, there were positive but non-significant correlations between the plasma caffeine levels and the magnitudes of decrease in CBF from pre-caffeine to 15 minutes post-caffeine $(r=+0.42)$, and from pre-caffeine to 45 minutes post-caffeine $(r=+0.35)$. A linear regression analysis of the change in whole brain CBF (ml/min/100 $\mathrm{gm}$ of tissue) in response to caffeine as a function of pre-caffeine whole brain CBF revealed the following relationship: Change in CBF $=$ (pre-caffeine CBF -29.4$) /(1.21) ; R^{2}=0.91$, $p<0.0005$. Differences among subjects in plasma caffeine levels attained did not account for this relationship.

No significant right versus ieft, or anterior versus posterior, cortical hemispheric differences were observed, either before or after caffeine infusion, and magnitude of the caffeine effect did not differ significantly among the cortical and subcortical RoIs analyzed. Patients had slightly higher whole-brain CBF levels than normal subjects (12\%), which was completely due to the higher CBF in the two female patients. Higher CBF in women has been reported previously $(28,29)$.

Results for the other dependent variables are presented in Table 1 . Based on all eight subjects given intravenous caffeine, caffeine produced a significant decrease in $\mathrm{p}_{\mathrm{a}} \mathrm{CO}_{2}(\mathrm{~F}=3.67$, df $=3,18, \mathrm{p}<0.03)$, and a significant increase in systolic blood pressure ( $F=9.11, \mathrm{df}=3,18, p<0.001)$. Trends were observed for increases in diastolic blood pressure $(F=2.86$, $d f=3,18, p<0.07)$ and anxiety level ( $F=2.61$, $d f=3,18, p<0.08)$. The small increases in heart rate and plasma catecholamine levels did not reach statistical significance. For these variables normal subjects differed from patients only for anxiety level ( $F=10.2$, df $=1,6, p<0.02)$, with patients 
higher than normal subjects; no other variable demonstrated even a trend towards a significant difference.

Table 1

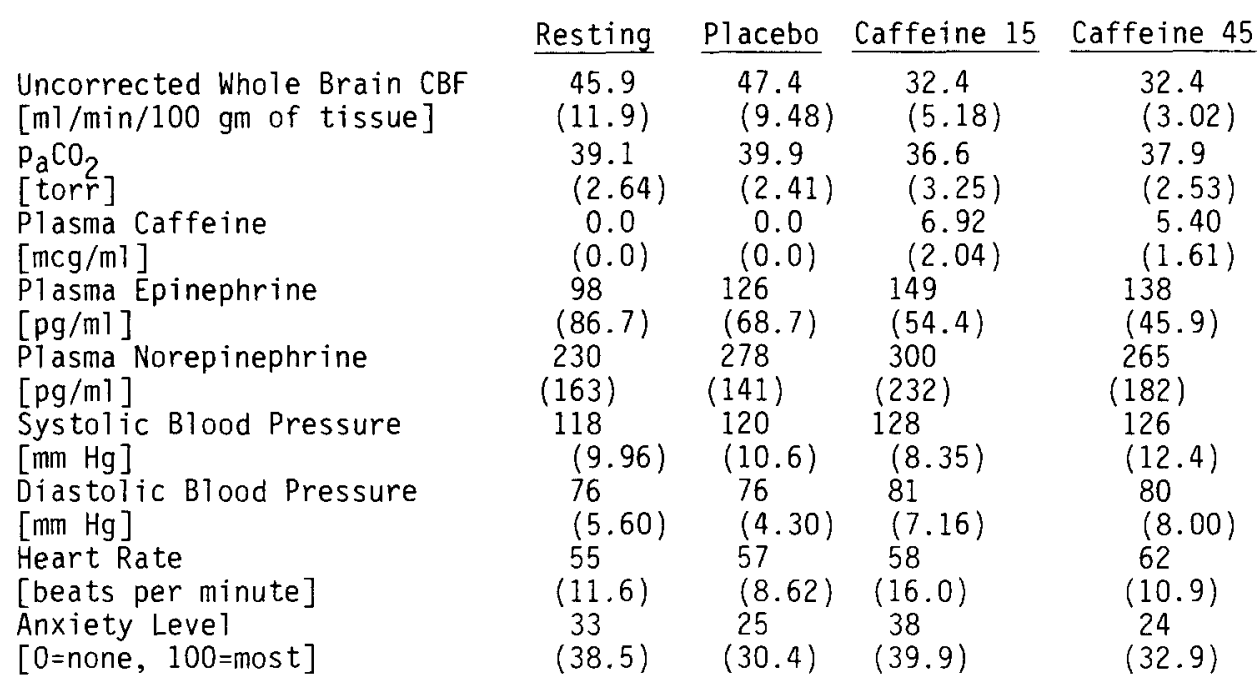

Mean Levels (and Standard Deviations) for $\mathrm{p}_{a} \mathrm{CO}_{2}$-Uncorrected Whole Brain CBF, Arterial $\mathrm{p}_{\mathrm{a}} \mathrm{CO}_{2}$, Arterial $\mathrm{Pl}$ asma Caffeine, Epinephrine, and Norepinephrine, Systolic and Diastolic Blood Pressures, Heart Rate, and Anxiety Severity for the Eight Subjects Given Intravenous Caffeine

For the two subjects given oral caffeine, average decreases for $\mathrm{p}_{\mathrm{a}} \mathrm{CO}_{2}$-corrected $\mathrm{CBF}$ were $32 \%, 36 \%$, and $34 \%$ at 15,45 , and 75 minutes following caffeine administration, respectively (repeated-measures $F=52.0, \mathrm{df}=3,3$, $p<0.005)$. Caffeine plasma levels were $4.65,4.91$, and $5.80 \mathrm{mcg} / \mathrm{ml}$, respectively. Changes in heart rate, blood pressure, and subjective anxiety were also comparable to the other normal subjects.

\section{Discussion}

Robust decreases in whole-brain CBF were observed following caffeine administration. By using PET methodology, this is the first study which has quantified the absolute magnitude of this decrease, and has performed regional cortical and subcortical analyses of changes in $C B F$ produced by caffeine. These decreases in CBF were produced by commonly consumed amounts of caffeine that do not produce impairment of cognitive performance $(18,30)$; oral and intravenous caffeine in the same doses produced CBF decreases of approximately equal magnitude. Since multiple scans do not produce a consistent change in $\mathrm{CBF}(31)$, the observed results were not due to repeated scans. Regional differences in effect of caffeine on CBF were not apparent; a larger study would be needed to verify that there are no regional differences in sensitivity of cerebral blood flow to caffeine. The magnitude of the caffeineinduced decrease was somewhat dependent on the plasma caffeine level at the time of scanning, but was not accounted for by the decrease in $\mathrm{p}_{\mathrm{a}} \mathrm{CO}_{2}$; even after $\mathrm{PaCO}_{2}$ correction, $66 \%$ of the variance in $\mathrm{CBF}$ upon repeated scans was accounted for by the caffeine effect. The decrease in CBF was strongly dependent on the pre-caffeine CBF, suggesting that some regulatory mechanism 
may prevent decreases below some minimum tolerable level (32); this level was approximately $30 \mathrm{ml} / \mathrm{min} / 100 \mathrm{gm}$ of tissue in this study.

Caffeine produced a significant increase in systolic blood pressure, as well as a significant decrease in $\mathrm{p}_{2} \mathrm{CO}_{2}$; heart rate and plasma catecholamines were non-significantly increased. however, none of these effects appear to account for the results observed; neither blood pressure increases of the magnitude observed in this study (33-35) nor changes of plasma catecholamine levels in brain vasculature (36) appear to influence $\mathrm{CBF}$, and, as already indicated, results were adjusted for the decrease in $\mathrm{p}_{a} \mathrm{CO}_{2}$. Based on prior research, it appears most likely that adenosinergic mechanisms mediate the effect of caffeine on CBF. Interestingly, al though in many circumstances CBF and cerebral glucose metabolic rate are closely coupled $(37,38)$, two prior studies suggest that caffeine does not affect cerebral glucose metabolism $(39,40)$; further research is needed to determine if caffeine provides a pharmacological agent which reliably dissociates CBF from cerebral glucose metabolism.

Based on all eight subjects given intravenous caffeine there was a trend towards a significant increase in subjective anxiety ratings in response to intravenously administered caffeine, and, as expected, anxiety level (but no other dependent variable) was significantly higher for patients than for normal subjects. There was, however, no consistent relationship between CBF and subjective anxiety, before or after caffeine administration. The small difference in CBF between patients and normal subjects appeared to be due solely to the higher CBF in the female versus the male subjects; a larger study is needed to verify that the CBF response to caffeine is not different in panic patients than in normal subjects.

[The authors thank the faculty and staff of the PET Facility, Section of Nuclear Medicine, Department of Internal Medicine, University of Michigan Medical Center for their assistance in the compietion of this study, and Stephen Schmaltz, M.S., of the University of Michigan Clinical Research Center for his statistical advice. This research was supported in part by NINCDS grant number NS 15655 (David E. Kuhl, M.D., Principal Investigator). A portion of this research was reported at the 1988 annual meeting of the American Psychiatric Association.]

\section{References}

1. T.W. RALL, The Pharmacological Basis of Therapeutics, ed 7. A.G. GILMAN, L.S. GOODMAN, T.W. RALL, F. MURAD (eds), 589-603, The MacMillan Publishing Co, Inc, New York (1985).

2. R.M. GILBERT, The Methylxanthine Beverages and Foods: Chemistry, Consumption, and Health Effects. G.A. SPILLER (ed), 185-213, Alan R. Liss, Inc, New York (1984).

3. J. BLANCHARD, S.J.A. SAWERS, Eur. J. Clin. Pharmacol. 24 93-98 (1983).

4. F.A. GIBBS, E.L. GIBBS, W.G. LENNOX, Am. Heart J. 10 916-924 (1935).

5. H.A. SHENKIN, J. App 7. Physiol. 3 465-471 (1951).

6. R.J. MATHEW, D.L. BARR, M.L. WEINMMAN, Br. J. Psychiatry 143 604-608 (1985).

7. D. ROBERTSON, J.C. FROLICH, R.K. CARR, J.T. WATSON, J.W. HOLLIFIELD, D.J. SHAND, J.A. OATES, N. Engl. J. Med. 298 181-186 (1978).

8. D. ROBERTSON, G.A. JOHNSON, R.M. ROBERTSON, A.S. NEIS, D.G. SHAND, J.A. OATES, Circulation 59 637-643 (1979).

9. S.H. SNYDER, P. SKLAR, J. Psychiatr.Res. 18 91-106 (1984). 
10. J.P. BOULENGER, P.J. MARANGOS, J. PATEL, T.W. UHDE, R.M. POST, Psychopharmaco1. Bul1. 20(3) 431-435 (1984).

11. R.J. GOULD, K.M.M. MURPHY, J.J. KATIMS, S.H. SNYDER, Psychopharmacol. BU77. 20(3) 436-440 (1984).

12. P.J. MARANGOS, J.P. BOULENGER, Neurosci. Biobehav. Rev. 9 421-430 (1985).

13. J.W. PHILlis, G. PRESTON, R.E. DELONG, J. Cereb. Blood FTow Metab. $\underline{4}$ 586-592 (1984).

14. J.W. PHILLIS, R.E. DELONG, Gen. Pharmacol. 18 133-139 (1987).

15. J.W. PHILLIS, R.E. DELONG, J. Pharm. Pharmacol. 38 460-462 (1986).

16. R.F. BRUNS, J.J. KATIMS, Z. ANNAU, S.H. SNYDER, J.W. DALY, NeuropharmaCology 22 1523-1529 (1983).

17. B.S. VICTOR, M. LUBETSKY, J.F. GREDEN, J. C1in. Psychiatry 42 185-188 (1981).

18. D.A. SAWYER, H.L. JULIA, A.C. TURIN, J. Behav. Med. 5 415-439 (1982).

19. J.P. BOULENGER, T.W. UHDE, E.A. WOLFF, R.M. POST, Arch. Gen. Psychiatry 41 1067-1071 (1984).

20. D.S. ChaRney, G.H. Heninger, P.I. JATlOW, Arch. Gen. Psychiatry 42 233-243 (1985).

21. M.A. LEE, O.G. CAMERON, J.F. GREDEN, Psychiatry Res. 15 211-217 (1985).

22. E.M. REIMAN, M.E. RAICHLE, E. ROBINS, F.K. BUTLER, P. HERSCDVITCH, P. FOX, J. PERLMUTTER, Am. J. Psychiatry 143 469-477 (1986).

23. R.C. GUR, R.E. GUR, S.M. RESNICK, B.E. SKOLNICK, A. ALAVI, M. REIVICH, J. Cereb. Blood Flow Metab. 7 173-177 (1987).

24. R.J. MATHEW, W.W. WILSON, Psychiatry Res. 23 285-294 (1988).

25. E.M. REIMAN, M.J. FUSSELMAN, P.T. FOX, M.E. RAICHLE, Science 243 1071-1074 (1989).

26. J.M. MOUNTZ, J.G. MODELL, M.W. WILSON, G.C. CURTIS, M.A. LEE, S.SCHMALTZ, D.E. KUHL, Arch. Gen. Psychiatry 46 501-504 (1989).

27. M. ROBERTS, J. HANAWAY, D.K. MOREST, Atlas of the Human Brain in Section, 2nd ed, Lea \& Febiger, Philadelphia (1987).

28. R.C. GUR, R.E. GUR, W.D. OBRIST, J.P. HUNGERBUHLER, D. YOUNKIN, A.D. ROSEN, B.E. SKOLNICK, M. REIVICH, Science 217 659-661 (1982).

29. R.J. MATHEW, W.H. WILSON, S.R. TANT, Biol. PSychiatry $21907-914$ (1986).

30. J.T. KUZNICKI, L.S. TURNER, Physiol. Behav. 37 397-408 (1986).

31. O.G. CAMERON, J.G. MODELL, R.D. HICHWA, B.W. AGRANOFF, R.A. KOEPPE, J. Cereb. Blood Flow Metab. 10 38-42 (1990).

32. G. BOYSEN, H.C. ENGELL, G.R. PISTOLESE, P. FIORANI, A. AGNOLI, N.A. LASSEN, Circulation 44 1023-1025 (1974).

33. S. STRANDGAARD, Brain and Heart Infarct. K.J. ZULCH, W. KAUJMANN, K.A. HOSSMANN, V. HOSSMANN (eds), 185-196, Springer-Verlag, Berl in (1977).

34. G. REED, M. DEVOUS, Am. J. Med. Sci. 289 37-44 (1985).

35. D. I. BARRY, J. Cardiovas. Pharmacol. 7 s94-s98 (1985).

36. J. OLESEN, Neurology 22 978-987 (1972).

37. R.M.BERNE, H.R. WINN, R. RUBIO, Prog. Cardiovas. Dis. 24 243-260 (1981).

38. J.C. MAZZIOTA, M.E. PHELPS, Positron Emission Tomography and Autoradiography: Principles and Applications for the Brain and Heart, M.E. PHELPS, J.C. MAZZIOTA, H.R. SCHELBERT (eds), 493-579, Raven Press, New York (1986).

39. A. NEHLig, G. LUCignani, M. KADEKARO, L.J. PORRINO, L. SOKOLOFF, Eur. J. Pharmacol. 101 91-100 (1984).

40. J.J. GROME, V. STEFANOVICH, Naunyn-Schiedeberg's Arch. Pharmacol. 333 $172-177$ (1986). 